\title{
Low or Adequate Carbohydrate Diet and Aerobic Exercise Decrease Cardiometabolic Risk in Overweight Women: A Randomized Controlled Clinical Trial
}

\section{Raquel Simões Mendes-Netto ${ }^{1,2}$, Ana Carolina Santos Barbosa Machado ${ }^{1}$, Bárbara Lúcia Fonseca Chagas $^{1}$, Marina de Macedo Rodrigues Leite ${ }^{1}$, Alan Bruno Silva Vasconcelos ${ }^{3}$, Danielle Góes da Silva ${ }^{2}$ and Marzo Edir da Silva Grigoletto ${ }^{1,3^{*}}$}

\author{
${ }^{1}$ Department of Physical Education, Federal University of Sergipe, Brazil \\ ${ }^{2}$ Department of Nutrition, Federal University of Sergipe, Brazil \\ ${ }^{3}$ Department of Physiology, Federal University of Sergipe, Brazil
}

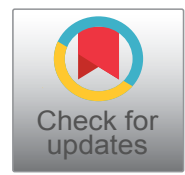

*Corresponding author: Marzo Edir da Silva Grigoletto, M.E., Center of Biological and Health Sciences, Department of Physical Education, Federal University of Sergipe, Cidade Universitária Prof. José Aloísio de Campos, Av. Marechal Rondon, s/n Jardim Rosa Elze, 49100-000, São Cristóvão, Sergipe, Brazil

\begin{abstract}
Aims: To evaluate the efficacy of a low carbohydrate diet on body composition and cardiometabolic markers in overweight women undergoing endurance physical training.

Subjects/Methods: A randomized, controlled clinical trial included 24 overweight women, 8 of whom consumed low-calorie diets containing an adequate carbohydrate content, while 16 consumed a low carbohydrate diet. The women regularly performed semi-supervised physical exercise (walking/running) for 12 weeks. Body composition (weight, abdominal and hip circumferences) and cardiometabolic parameters were analyzed. Data were analyzed using a two-way analysis of variance with the Bonferroni post-hoc test. A p value $<0.05$ indicated statistical significance.

Results: After 12 weeks, both groups exhibited significant reductions $(p<0.05)$ in body mass (A-CHO: $-9.86 \%$; L-CHO: - 8.48\%), abdominal (A-CHO: - 7.48\%; L-CHO: $8.05 \%$ ) and hip circumferences, fat percentage (A-CHO: 7.32\%; L-CHO: - 9.15\%), and liver function marker levels (AST: A-CHO: - 12.24\%; L-CHO: - 11.26\%; ALT: A-CHO: - 6.48\%; L-CHO: - 11.93\%), as well as improved lipid profiles. However, no differences were observed in the anthropometric and biochemical variables regarding to the carbohydrate content $(p>0.05)$.

Conclusion: The combination of a hypocaloric diets with jogging effectively promoted weight loss and improved
\end{abstract}

cardiometabolic risk parameters, regardless of the carbohydrate content of the diet.

Brazilian Clinical Trials Registry (Registration No. RBR5n9g5f).

\section{Introduction}

Overweight, which has led to increases in morbidity and mortality consequent to cardiometabolic changes, is among the most significant public health issues worldwide. Among food-related factors, a higher energy intake and associated lower caloric expenditure contribute to a positive energy balance and subsequent weight gain [1-4].

Current research indicates that hypocaloric diets involving manipulations of the carbohydrate content contribute uniquely to weight loss and cardiometabolic profile improvements and have been shown to be more efficient than fat-restricted diets [3,5-13]. It is considered as a low carbohydrate diet, those in which this nutrient contribution is $\leq 45 \%$ of the total energy intake [11,14].

However, in the presence of severe carbohydrate

Citation: Mendes-Netto RS, Machado ACSB, Chagas BLF, Leite MMR, Vasconcelos ABS, et al. (2019) Low or Adequate Carbohydrate Diet and Aerobic Exercise Decrease Cardiometabolic Risk in Overweight Women: A Randomized Controlled Clinical Trial. Int J Sports Exerc Med 5:146. doi.org/10.23937/24695718/1510146

Accepted: October 02, 2019; Published: October 04, 2019

Copyright: (C) 2019 Mendes-Netto RS, et al. This is an open-access article distributed under the terms of the Creative Commons Attribution License, which permits unrestricted use, distribution, and reproduction in any medium, provided the original author and source are credited. 
restriction (carbohydrate intake $<20 \mathrm{~g} /$ day or $<5 \%$ of the daily intake), unsatisfactory effects such as a lack of enthusiasm for physical activity, subsequent weight gain, and low adherence to dietary follow-up, have been observed [6,15-19]. Other studies have shown that compared with other types of diets, a reduction in dietary carbohydrate intake and corresponding increase in saturated fat intake could damage the cardiometabolic profile, leading to increases in the levels of markers such as low-density lipoprotein cholesterol [20]. In contrast, other studies have demonstrated improvements in the cardiometabolic condition, as indicated increased high-density lipoprotein cholesterol levels, decreased C-reactive protein levels, and increased adiponectin levels $[12,13]$.

For adults, the Dietary Reference Intake for macronutrients suggests a minimum daily carbohydrate intake of $130 \mathrm{~g}$ per day and/or $45-65 \%$ of the total dietary energy intake [21]. Given this wide range, the minimum amount of carbohydrates required to confer positive effects, such as an improved body composition and cardiometabolic parameters, remains controversial.

Therefore, we presumed that defining a dietary macronutrient distribution protocol would strengthen the nutrition strategies for overweight/obese patients, thus allowing greater control over their treatment and preventing deterioration of their conditions. This study aimed to evaluate the effects of dietary carbohydrate reduction on body composition and cardiometabolic markers in overweight women undergoing endurance physical training.

\section{Materials and Methods}

\section{Sample}

This randomized controlled clinical trial included adult women enrolled from among the students, professors, and staff of the university. Although we identified 361 interested potential participants, only 106 met the inclusion criteria of an age between 18 and 59 years, sedentary status, body mass index between

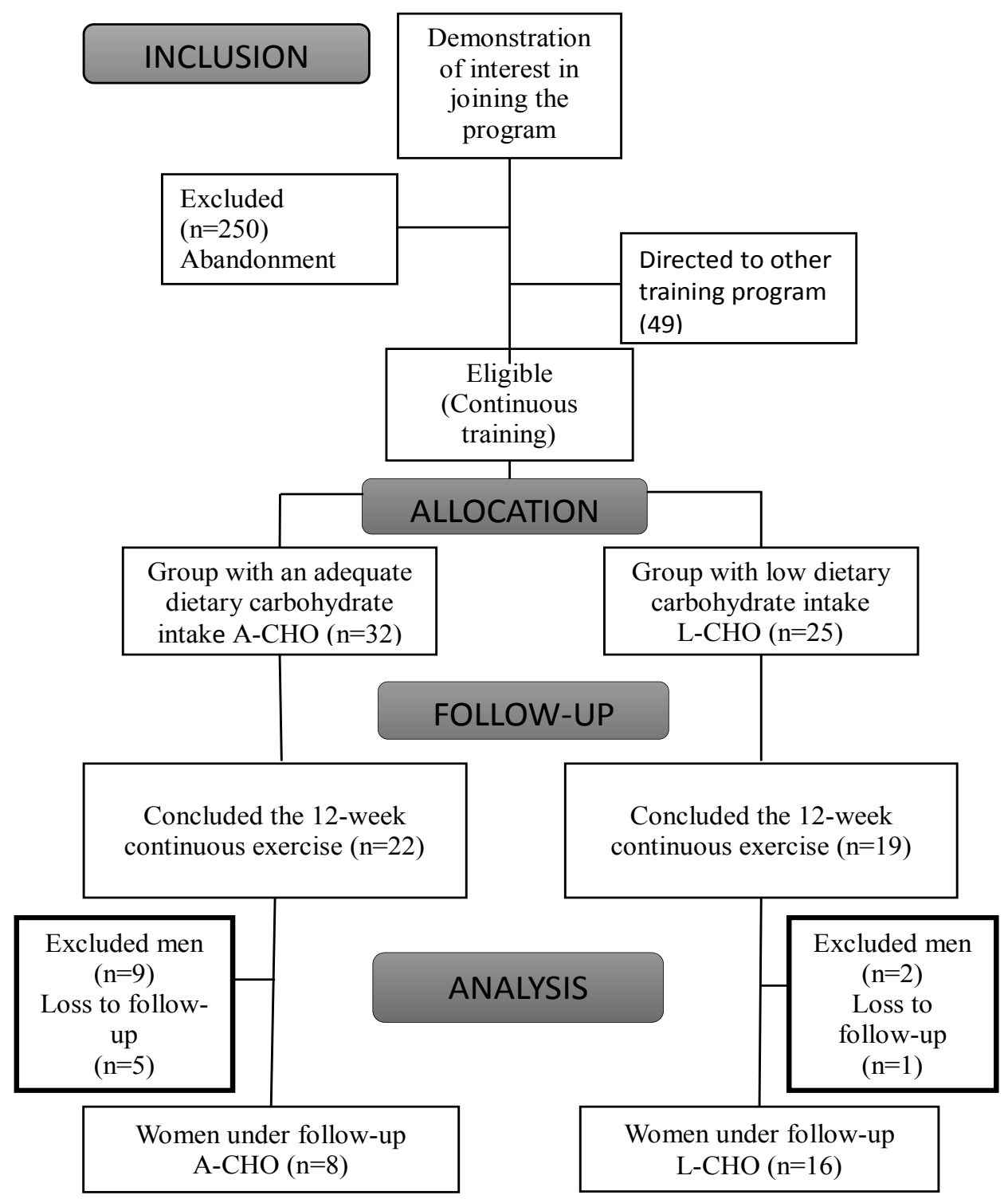

Figure 1: CONSORT Flow chart of the 12-week intervention. 
$25 \mathrm{~kg} / \mathrm{m}^{2}$ and $39.9 \mathrm{~kg} / \mathrm{m}^{2}$, and no weight fluctuations exceeding $\pm 3 \%$ during the last 3 months. Participants who required medical or nutrition support, had nutritional disorders, and/or used anorectic drugs and/ or hormonal medications were excluded. The participants were assigned to 2 different groups, randomized by age, sex and BMI, according to the level of carbohydrate included in their diet. During the 12 weeks of intervention, six volunteers left the program under personal reasons, also all men were excluded for analyses, since only 2 men remained in the low-carbohydrate group after the intervention (Figure 1).

The sample calculation was carried out and demonstrated that the minimum of 22 patients should enter the study for a power of 0.8 and an $82 \%$ of probability of detecting a treatment difference [11].

This study followed the recommendations of the Declaration of Helsinki and the National Health Council no. $466 / 2012$, and was approved by the ethics committee of the research university at which the study was conducted (23421113.1.0000.5546). This study was also registered in the Rebec (Registry of Brazilian Clinical Trials) database under no. RBR-5n9g5f. All participants received an explanation of the study procedures and provided written informed consent.

\section{Experimental design}

The individuals were evaluated at the baseline (M0) and after a 12-week intervention (M1). Anthropometric, dietary, and blood measurements were performed at both time points. Once a month during the 12-week period, the participants underwent individualized nutritional consultations with average durations of 30-40 minutes (Week 1 [W1], Week 5 [W5], Week 9 [W9]), during which the weight and hip circumference were measured and a 24-hour dietary recall was performed. Concurrently, attendance at thrice-weekly training sessions was recorded, and all participants' weights were recorded once weekly. Participants who did not attend the nutritional consultations and/or had more than 2 consecutive absences or 4 sporadic absences in the training program during the 12 -week period were asked to withdraw from the study.

\section{Dietary protocol}

The caloric restriction protocol was based on achieving a body weight reduction of $5-10 \%$ within 12 weeks, with a restriction of 500 or $1000 \mathrm{kcal} /$ day for overweight and obese individual [22], respectively. The basal metabolic rate was individually calculated by the formula proposed by the Institute of Medicine [21].

The carbohydrate content varied between the two groups. For the adequate carbohydrate content ( $\mathrm{A}-\mathrm{CHO})$ group, the caloric contributions of carbohydrates, protein, and lipids were set at $55 \%, 27 \%$, and $19 \%$ of the total calorie intake, respectively. The Low Carbohydrate
Content ( $\mathrm{L}-\mathrm{CHO}$ ) group received a dietary plan that allowed for caloric contributions of $25 \%, 48 \%$, and $28 \%$ for carbohydrates, proteins, and lipids, respectively. The participants were encouraged to follow the assigned food plans, and intake was monitored via dietary records and food plan adherence questionnaires. During dietary follow-up, the groups were further divided based on the mean final carbohydrate intake of $130 \mathrm{~g}$ per day.

\section{Training protocol}

A semi-supervised training program was proposed in this study. Three weekly sessions were performed for 12 weeks, with a duration of 60 minutes and a recovery time of 48 hours between sessions. The training sessions were conducted twice weekly under the supervision of technical staff and once weekly by the volunteers themselves in a place of their preference [23]. The intensity was controlled by the Borg scale [24] and the heart rate using the Polar Team2 system (Polar Electro ${ }^{\circledR}$, Kempele, Finland).

Participants received individualized training sheets with guidance regarding the heart rate for each week of training. To control heart rate in training 3 (at home), participants received an individual polar (Polar Electro ${ }^{\circledR}$, Kempele, Finland). The participants were required to practice continuous exercise, they began training at $65 \%$ of their maximum heart rate (MHR), with $5 \%$ increases over 4 weeks to $75 \%$ of their MHR at the completion of the 12-week program. The intensity was controlled individually using a heart rate monitor (watch) connected to a computer program, the data observed was used by the technical staff to alert the volunteer to increase or decrease the intensity of the exercise (Table 1).

\section{Anthropometric and cardiometabolic evaluation}

At the initial (M0) and final (M1) evaluations, weight was measured using a digital scale (Lider ${ }^{\circledR}, \mathrm{P} 150 \mathrm{C}$, Brazil) with a precision of $100 \mathrm{~g}$. The abdominal and hip circumferences were evaluated using an inelastic tape (SANNY ${ }^{\circledR}$, American Medical do Brasil Ltda) [25]. Body composition was measured via electrical bioimpedance (Biodynamics ${ }^{\circledR} 310$ e, Corporation, EUA). In addition, 12$\mathrm{mL}$ blood samples were collected via venipuncture from an antecubital vein after a 12-hour fast. The lipid profile (total cholesterol, very low-density lipoprotein cholesterol, low-density lipoprotein cholesterol, high-density lipoprotein cholesterol, and free triacylglycerols) and levels of hepatic profile markers (aspartate transaminase and alanine transaminase), blood glucose, uric acid, urea, and creatinine were measured. All blood tests were performed using an Immunoassay Analyzer (Abbott Architect i1000SR Analyzer, USA).

\section{Statistical analysis}

For all statistical analyses, a $p$ value of $<0.05(5 \%)$ indicated statistical significance. SPSS software, ver- 
Table 1: Periodization for 12 weeks of endurance training.

\begin{tabular}{|c|c|c|c|c|}
\hline Week & $\begin{array}{l}\text { Intensity } \\
(\% \mathrm{MHR})\end{array}$ & $\begin{array}{l}\text { Session } 1 \\
(\min )\end{array}$ & $\begin{array}{l}\text { Session } 2 \\
(\min )\end{array}$ & $\begin{array}{l}\text { Session } 3^{*} \text { (at home) } \\
(\min )\end{array}$ \\
\hline 1 & 65 & 20 & 25 & 30 \\
\hline 2 & 65 & 25 & 30 & 35 \\
\hline 3 & 65 & 30 & 35 & 40 \\
\hline 4 & 65 & 35 & 40 & 45 \\
\hline 5 & 70 & 20 & 25 & 30 \\
\hline 6 & 70 & 25 & 30 & 35 \\
\hline 7 & 70 & 30 & 35 & 40 \\
\hline 8 & 70 & 35 & 40 & 45 \\
\hline 9 & 75 & 20 & 25 & 30 \\
\hline 10 & 75 & 25 & 30 & 35 \\
\hline 11 & 75 & 30 & 35 & 40 \\
\hline 12 & 75 & 35 & 40 & 45 \\
\hline
\end{tabular}

MHR = Maximum Heart Rate; $\min =$ minutes. ${ }^{~ i n ~ t h e ~ a t ~ h o m e ~ t r a i n i n g ~ s e s s i o n ~ t h e ~ i n t e n s i t y ~ w a s ~} 5 \%$ lower than in the faceto-face sessions.

Table 2: Pre- and post-intervention anthropometric and body composition variables of overweight women according to diet type (A-CHO and L-CHO).

\begin{tabular}{|c|c|c|c|c|c|}
\hline & \multicolumn{2}{|l|}{ (Mean (SE)) } & \multicolumn{3}{|l|}{ ANOVA } \\
\hline & $\begin{array}{l}\mathrm{A}-\mathrm{CHO} \\
\mathrm{n}=08\end{array}$ & $\begin{array}{l}\mathrm{L}-\mathrm{CHO} \\
\mathrm{n}=16\end{array}$ & $\begin{array}{l}G \\
F(p)\end{array}$ & $\begin{array}{l}T \\
F(p)\end{array}$ & $\begin{array}{l}\text { GxT } \\
F(p)\end{array}$ \\
\hline \multicolumn{6}{|c|}{ Body Mass (kg) } \\
\hline Pre & $77.77 \pm 17.38$ & $78.77 \pm 11.47$ & $0.06(0.23)$ & $99.72(<0.001)$ & $0.10(0.75)$ \\
\hline Post & $70.28 \pm 17.44$ & $72.18 \pm 11.48$ & & & \\
\hline$\Delta \%$ & -9.86 & -8.48 & & & \\
\hline ES & 0.52 & 0.54 & & & \\
\hline \multicolumn{6}{|c|}{ BMI (Kg/m²) } \\
\hline Pre & $31.02 \pm 6.25$ & $32.41 \pm 3.95$ & $0.57(0.45)$ & $83.51(<0.001)$ & $0.70(0.41)$ \\
\hline Post & $27.97 \pm 6.05$ & $29.66 \pm 3.88$ & & & \\
\hline$\Delta \%$ & -9.86 & -8.48 & & & \\
\hline ES & 0.54 & 0.72 & & & \\
\hline \multicolumn{6}{|c|}{$\begin{array}{l}\text { Abdominal } \\
\text { circumference }(\mathrm{cm})\end{array}$} \\
\hline Pre & $97.12 \pm 16.72$ & $101.4 \pm 10.53$ & $0.50(0.48)$ & $109.03(<0.001)$ & $0.39(0.53)$ \\
\hline Post & $89.85 \pm 15.78$ & $93.32 \pm 11.04$ & & & \\
\hline$\Delta \%$ & -7.48 & -8.05 & & & \\
\hline ES & 0.61 & 0.74 & & & \\
\hline \multicolumn{6}{|c|}{ Hip circumference } \\
\hline Pre & $113.56 \pm 11.88$ & $109.88 \pm 7.07$ & $0.39(0.53)$ & $70.88(<0.001)$ & $0.10(0.75)$ \\
\hline Post & $105.91 \pm 11.98$ & $104.55 \pm 8.62$ & & & \\
\hline$\Delta \%$ & -6.76 & -4.91 & & & \\
\hline ES & 0.60 & 0.67 & & & \\
\hline \multicolumn{6}{|c|}{$\%$ Fat (\%) } \\
\hline Pre & $36.46 \pm 4.52$ & $37.23 \pm 4.24$ & $0.03(0.84)$ & $46.59(<0.001)$ & $0.00(0.99)$ \\
\hline Post & $33.86 \pm 5.13$ & $33.84 \pm 4.60$ & & & \\
\hline$\Delta \%$ & -7.32 & -9.15 & & & \\
\hline ES & 0.57 & 0.79 & & & \\
\hline
\end{tabular}




\begin{tabular}{|l|l|l|l|l|l|}
\hline FM $\mathbf{( K g )}$ & & & & \\
\hline Pre & $28.61 \pm 9.94$ & $29.51 \pm 6.47$ & $0.03(0.85)$ & $101.35(<0.001)$ & $0.008(0.93)$ \\
\hline Post & $24.42 \pm 9.75$ & $24.71 \pm 6.34$ & & & \\
\hline$\Delta \%$ & -15.63 & -16.64 & & & \\
\hline ES & 0.61 & 0.79 & & & $0.28(0.60)$ \\
\hline LM (kg) & & & & \\
\hline Pre & $48.41 \pm 8.42$ & $49.26 \pm 6.61$ & $0.16(0.69)$ & & \\
\hline Post & $45.86 \pm 8.04$ & $47.47 \pm 6.43$ & & & \\
\hline$\Delta \%$ & -5.22 & -3.62 & & & \\
\hline ES & 0.18 & 0.22 & & & \\
\hline
\end{tabular}

A-CHO: Adequate Carbohydrate Content; L-CHO: Low Carbohydrate content; ES: Effect Size; G: group; T: time; G×T: interaction effect of $G$ and T; BMI: Body Mass Index; FM: Fat Mass; LM: Lean Mass; F: F value of the test.

Table 3: Pre- and post-intervention biochemical variables of overweight women according to diet type (A-CHO and L-CHO).

\begin{tabular}{|c|c|c|c|c|c|}
\hline & \multicolumn{2}{|l|}{ (Mean (SE)) } & \multicolumn{3}{|l|}{ ANOVA } \\
\hline & $\begin{array}{l}\text { A-CHO } \\
n=08\end{array}$ & $\begin{array}{l}\mathrm{L}-\mathrm{CHO} \\
\mathrm{n}=16\end{array}$ & $\begin{array}{l}G \\
F(p)\end{array}$ & $\begin{array}{l}T \\
F(p)\end{array}$ & $\begin{array}{l}\text { GxT } \\
F(p)\end{array}$ \\
\hline \multicolumn{6}{|c|}{$\mathrm{TC}$ (mg/dL) } \\
\hline Pre & $198.62 \pm 41.00$ & $195.81 \pm 19.84$ & $0.005(0.94)$ & $23.33(<0.001)$ & $0.11(0.73)$ \\
\hline Post & $169.00 \pm 32.05$ & $173.62 \pm 30.87$ & & & \\
\hline$\Delta \%$ & -14.41 & -10.67 & & & \\
\hline ES & 0.70 & 0.68 & & & \\
\hline \multicolumn{6}{|c|}{ VLDL-c (mg/dL) } \\
\hline Pre & $23.00 \pm 17.75$ & $24.25 \pm 9.01$ & $0.21(0.65)$ & $13.34(0.001)$ & $0.61(0.44)$ \\
\hline Post & $15.37 \pm 7.38$ & $17.75 \pm 6.80$ & & & \\
\hline$\Delta \%$ & -20.38 & -21.60 & & & \\
\hline ES & 0.76 & 0.82 & & & \\
\hline \multicolumn{6}{|c|}{ LDL-c (mg/dL) } \\
\hline Pre & $117.75 \pm 25.95$ & $113.06 \pm 28.33$ & $0.035(0.85)$ & $28.68(<0.001)$ & $0.003(0.95)$ \\
\hline Post & $91.87 \pm 24.48$ & $92.50 \pm 27.07$ & & & \\
\hline$\Delta \%$ & -21.81 & -17.47 & & & \\
\hline ES & 0.76 & 0.68 & & & \\
\hline \multicolumn{6}{|c|}{ HDL-c (mg/dL) } \\
\hline Pre & $57.87 \pm 9.26$ & $58.50 \pm 12.00$ & $0.06(0.79)$ & $8.11(0.009)$ & $0.14(0.71)$ \\
\hline Post & $61.75 \pm 10.19$ & $63.37 \pm 9.87$ & & & \\
\hline$\Delta \%$ & 6.96 & 9.28 & & & \\
\hline ES & 0.55 & 0.47 & & & \\
\hline \multicolumn{6}{|c|}{ TG (mg/dL) $)^{b}$} \\
\hline Pre & $84.28 \pm 28.22$ & $120.50 \pm 45.29$ & $4.22(0.05)$ & $10.66(0.004)$ & $2.88(0.10)$ \\
\hline Post & $65.71 \pm 20.43$ & $89.19 \pm 33.69$ & & & \\
\hline$\Delta \%$ & -19.50 & -20.37 & & & \\
\hline ES & 0.76 & 0.79 & & & \\
\hline \multicolumn{6}{|c|}{ Glycemia (mg/dL) } \\
\hline Pre & $87.75 \pm 11.90$ & $91.25 \pm 8.69$ & $0.76(0.39)$ & $5.38(0.03)$ & $0.46(0.50)$ \\
\hline Post & $84.25 \pm 6.36$ & $86.18 \pm 6.64$ & & & \\
\hline$\Delta \%$ & -3.00 & -5.15 & & & \\
\hline ES & 0.25 & 0.56 & & & \\
\hline \multicolumn{6}{|c|}{ AST $(U / L)^{a}$} \\
\hline Pre & $26.50 \pm 4.40$ & $22.46 \pm 4.58$ & $3.13(0.09)$ & $12.72(0.002)$ & $1.41(0.24)$ \\
\hline
\end{tabular}




\begin{tabular}{|c|c|c|c|c|c|}
\hline Post & $22.87 \pm 3.87$ & $20.60 \pm 4.59$ & & & \\
\hline$\Delta \%$ & -12.24 & -11.26 & & & \\
\hline ES & 0.79 & 0.39 & & & \\
\hline \multicolumn{6}{|c|}{$\operatorname{ALT}(U / L)^{a}$} \\
\hline Pre & $23.00 \pm 8.07$ & $16.60 \pm 7.05$ & $5.27(0.03)$ & $1.84(0.18)$ & $3.46(0.07)$ \\
\hline Post & $20.50 \pm 8.45$ & $14.06 \pm 7.60$ & & & \\
\hline$\Delta \%$ & -6.48 & -11.93 & & & \\
\hline ES & 0.69 & 0.40 & & & \\
\hline \multicolumn{6}{|c|}{ Uric acid (mg/dL) } \\
\hline Pre & $3.68 \pm 0.65$ & $3.84 \pm 0.93$ & $0.12(0.72)$ & $1.28(0.26)$ & $0.07(0.79)$ \\
\hline Post & $3.55 \pm 0.61$ & $3.68 \pm 1.27$ & & & \\
\hline$\Delta \%$ & -2.78 & -4.85 & & & \\
\hline ES & 0.07 & 0.12 & & & \\
\hline \multicolumn{6}{|c|}{ Urea (mg/dL) } \\
\hline Pre & $21.00 \pm 4.03$ & $22.06 \pm 5.76$ & $0.03(0.84)$ & $0.41(0.52)$ & $0.02(0.88)$ \\
\hline Post & $22.37 \pm 3.96$ & $22.06 \pm 5.19$ & & & \\
\hline$\Delta \%$ & 8.55 & 2.73 & & & \\
\hline ES & 0.23 & 0.10 & & & \\
\hline \multicolumn{6}{|c|}{ Creatinine (mg/dL) } \\
\hline Pre & $0.70 \pm 0.11$ & $0.69 \pm 0.09$ & $0.78(0.38)$ & $9.50(0.005)$ & $2.38(0.13)$ \\
\hline Post & $0.67 \pm 0.10$ & $0.61 \pm 0.08$ & & & \\
\hline$\Delta \%$ & -2.46 & -11.32 & & & \\
\hline ES & 0.35 & 0.78 & & & \\
\hline
\end{tabular}

A-CHO: Adequate Carbohydrate Content; R-CHO: low carbohydrate content; ES: Effect Size; G: group; T: time; G×T: interaction F, F test; p, significance; TC: Total Cholesterol; VLDL-c: Very Low-Density Lipoprotein cholesterol; LDL-c: Low-Density Lipoprotein cholesterol; HDL-c: High-Density Lipoprotein cholesterol; TG: free triacylglycerols; AST: Aspartate Aminotransferase; ALT: Alanine Aminotransferase; ${ }^{a} \mathrm{R}-\mathrm{CHO}, \mathrm{n}=15 ;{ }^{\mathrm{b}} \mathrm{A}-\mathrm{CHO}, \mathrm{n}=7$.

sion 20 for Windows (Armonk, NY: IBM Corp) was used for the data analysis. Descriptive statistics, delta variations, and standard errors were used to compare data between groups and as a function of time. The Shapiro-Wilk test was used to determine data normality. A two-way analysis of variance and Bonferroni post-hoc test were used to compare the anthropometric and physical fitness data between groups $(G \times T)$, over time $(T)$, and within groups $(G)$.

The Effect Size (ES) was calculated as the mean of the difference divided by the mean of the standard deviations of the pre- and post-intervention timings. Absolute ES values (modulus) of 0.20-0.49, 0.50-0.79, and $>0.80$ were considered small, moderate, and large, respectively [26].

\section{Results}

Twenty-four overweight women participated in this study. The mean age were $32.19 \pm 9.55$ years in the A-CHO group and $29.37 \pm 12.28$ years in the $\mathrm{L}-\mathrm{CHO}$ group. The anthropometric data analysis (Table 1) showed significant reductions across the parameters as a function of time, with no significant differences between $\mathrm{A}-\mathrm{CHO}$ and $\mathrm{L}-\mathrm{CHO}$ groups.

Although participants from both groups exhibited significant decreases in lean mass over time, this re- duction had a low clinical effect $(E S<0.2)$. By contrast, changes in the abdominal circumference and body fat had higher effect sizes (ES: 0.5-0.79).

The participants also exhibited improved lipid profiles, with a decrease in total cholesterol, very low-density lipoprotein cholesterol, low-density lipoprotein cholesterol, and free triacylglycerol levels that were accompanied by a significant increase in high-density lipoprotein cholesterol over time $(T)$. However, the difference between the groups was not statistically significant (G×T; Table 2, Table 3).

Although a decrease in aspartate aminotransferase levels was observed in both groups over time, no GXT difference was observed. The alanine aminotransferase levels, however, differed between the L-CHO and A-CHO groups $(p=0.03)$. The uric acid and urea levels did not change over time or with respect to dietary intervention outcomes. However, both groups exhibited decreases in creatinine levels over the 12-week period.

\section{Discussion}

The main finding of the present study was that the combination of caloric restriction with an endurance physical training program yielded changes in body weight and body composition and improved 
the cardiometabolic profile, regardless of the dietary carbohydrate content. This finding agrees with those of previous studies indicating that moderate caloric restriction (300-500 kcal) appears to facilitate adherence to weight loss programs, regardless of the dietary carbohydrate content, and contribute to improvements in body composition and inflammation levels over a 12-week period [27-30].

Despite the different carbohydrate contents of the diets administered in the present study, the carbohydrate reduction proposed to the $\mathrm{L}-\mathrm{CHO}$ group was not intense when compared with ketogenic diets [12]. Therefore, the anthropometric and cardiometabolic profile parameters may have not been drastically affected, as the minimum limits recommended by the Dietary Reference Intake criteria ( $110 \mathrm{~g} /$ day or $45 \%$ of the total energy intake) were observed [21].

The participants exhibited changes in blood lipid profiles throughout the intervention period that did not interact with the dietary carbohydrate composition. Diets with moderate carbohydrate contents and those with severe restrictions seem to have similar short-term effects [31-33]. Over the long term, however, intense carbohydrate restriction appears to have a reduced effect on triacylglycerol levels [34,35].

In the present study, the hypocaloric diet designed to control carbohydrate intake may have led to a slower insulin release, thus promoting increased hepatic glucose degradation and the use of free fatty acids as an energy source by inhibiting the action of lipoprotein lipase [36]. The reduced release of insulin, in conjunction with a reduced dietary supply of energy and fats, may have also contributed to the reduced synthesis and release of blood lipids, such as cholesterol and triacylglycerol, in the form of lipoproteins [37].

Despite the importance of the dietary follow-up, the inclusion of regular physical exercise is well known to reduce the risk of chronic noncommunicable diseases by $6-10 \%$ while increasing the quality of life and life expectancy [21]. Adherence to dietary interventions $(\geq 80 \%)$ in association with physical activity potentiates a reduction in cardiometabolic risk [38,39].

The strengths of this study included the randomized design, carbohydrate reduction in compliance with dietary reference guidelines, dietary planning based on regional and financial aspects, and follow-ups conducted by health professionals to facilitate program adherence. However, this study was also limited by our inability to establish an experimental group with a very low carbohydrate intake $(<20 \mathrm{~g} / \mathrm{d})$ for comparison. Moreover, this condition would have required more intense monitoring of patients, which was not possible within the framework of our study.
In summary, changes in the carbohydrate compositions of diets need not be severe to affect body weight reduction. Furthermore, consumption of a hypocaloric diet within the recommended carbohydrate intake range over a 12-week period, when accompanied by regular physical exercise, could promote improvements in the lipid profiles of overweight women.

\section{Author Contributions}

RSMN and MESG designed research; ACSBM, BLFC and ABSV performed experiments; AGRN and MESG analyzed data; AGRN and JCAS interpreted results of experiments; RSMN, MMRL, ABSV and DGS drafted manuscript; ABSV and MESG edited and revised manuscript; RSMN and MESG approved final version of manuscript.

\section{Acknowledgements}

The authors would like to thank the members of the Laboratory of Clinical Analysis of the University Hospital of the Federal University of Sergipe for conducting the biochemical analyses. This study was supported by master degree scholarship and research Grant from FAPITEC/SE - (MS/CNPq/FAPITEC/SE/SES 02/2013 - PPSUS Sergipe).

\section{Conflict of Interest}

The authors declare that there is no conflict of interest.

\section{References}

1. Fontaine $K R$, Redden DT, Wang $C$, Westfall $A O$, Allison DB (2003) Years of life lost due to obesity. JAMA 289: 187-193.

2. Dixon JB (2010) The effect of obesity on health outcomes. Mol Cell Endocrinol 316: 104-108.

3. Garthe I, Raastad T, Sundgot-Borgen J (2011) Long-term effect of nutritional counselling on desired gain in body mass and lean body mass in elite athletes. Appl Physiol Nutr Metab 36: 547-554.

4. Casazza K, Cardel M, Dulin-Keita A, Hanks LJ, Gower BA, et al. (2012) Reduced Carbohydrate Diet to Improve Metabolic Outcomes and Decrease Adiposity in Obese Peripubertal African American Girls. J Pediatr Gastroenterol Nutr 54: 336-342.

5. Miller M, Beach V, Sorkin JD, Mangano C, Dobmeier C, et al. (2009) Comparative Effects of Three Popular Diets on Lipids, Endothelial Function, and C-Reactive Protein during Weight Maintenance. J Am Diet Assoc 109: 713-717.

6. Foster GD, Wyatt HR, Hill JO, Makris AP, Rosenbaum DL, et al. (2010) Weight and metabolic outcomes after 2 years on a low carbohydrate versus low-fat diet: a randomized trial. Ann Intern Med 153: 147-157.

7. Frisch S, Zittermann A, Berthold HK, Götting C, Kuhn J, et al. (2009) A randomized controlled trial on the efficacy of carbohydrate-reduced or fat-reduced diets in patients attending a telemedically guided weight loss program. Cardiovasc Diabetol 8: 36.

8. Volek JS, Quann EE, Forsythe CE (2010) Low-Carbohydrate Diets Promote a More Favorable Body Composition Than Low-Fat Diets: Strength Cond J 32: 42-47. 
9. Kirk SFL, Penney TL, McHugh T-L, Sharma AM (2012) Effective weight management practice: a review of the lifestyle intervention evidence. Int J Obes 36: 178-185.

10. Gu Y, Yu H, Li Y, Ma X, Lu J, et al. (2013) Beneficial Effects of an 8-Week, Very Low Carbohydrate Diet Intervention on Obese Subjects. Evid Based Complement Alternat Med 2013: 1-8.

11. Hu T, Mills KT, Yao L, Demanelis K, Eloustaz M, et al. (2012) Effects of Low-Carbohydrate Diets Versus Low-Fat Diets on Metabolic Risk Factors: A Meta-Analysis of Randomized Controlled Clinical Trials. Am J Epidemiol 176: 4454.

12. Ruth MR, Port AM, Shah M, Bourland AC, Istfan NW, et al. (2013) Consuming a hypocaloric high fat low carbohydrate diet for 12 weeks lowers C-reactive protein, and raises serum adiponectin and high density lipoprotein-cholesterol in obese subjects. Metabolism 62: 1779-1787.

13. Finelli C, Crispino P, Gioia S, La Sala N, D'amico L, et al. (2016) The improvement of large High-Density Lipoprotein (HDL) particle levels, and presumably HDL metabolism, depend on effects of low-carbohydrate diet and weight loss. EXCLI J 15: 166-176.

14. Hu T, Bazzano LA (2014) The low-carbohydrate diet and cardiovascular risk factors: evidence from epidemiologic studies. Nutr Metab Cardiovasc Dis NMCD 24: 337-343.

15. Strasser B, Berger K, Fuchs D (2015) Effects of a caloric restriction weight loss diet on tryptophan metabolism and inflammatory biomarkers in overweight adults. Eur J Nutr 54: 101-107.

16. Sundgot-Borgen J, Garthe I (2011) Elite athletes in aesthetic and Olympic weight-class sports and the challenge of body weight and body compositions. J Sports Sci 29: 101114.

17. Lowe MR (2015) Dieting: proxy or cause of future weight gain? Obes Rev 16: 19-24.

18. Butki BD, Baumstark J, Driver S (2003) Effects of a carbohydrate-restricted diet on affective responses to acute exercise among physically active participants. Percept Mot Skills 96: 607-615.

19. Clifton PM (2011) Low-carbohydrate diets for weight loss: the pros and cons. J Hum Nutr Diet 24: 523-524.

20. Bray GA, Siri-Tarino PW (2016) The Role of Macronutrient Content in the Diet for Weight Management. Endocrinol Metab Clin North Am 45: 581-604.

21. (2006) Dietary Reference Intakes: The Essential Guide to Nutrient Requirements. National Academies Press, Washington, D.C.

22. Associação Brasileira para o Estudo da Obesidade e da Síndrome Metabólica (2009) Diretrizes brasileiras de obesidade.

23. Leite M, Da Silva Grigoletto ME, Chagas B, Machado A, Santos-Silva R, et al. (2018) Perda de peso baseada na dieta com ou sem restrição de carboidratos, e exercício contínuo ou intermitente de alta intensidade: protocolo para um estudo clínico randomizado e controlado. Rev Andal Med Deporte 0.

24. Borg G (2000) Escalas de Borg para a dor e o esforço: percebido. Manole, São Paulo.

25. Lohman TG, Roche AF (1988) Anthropometric standardization reference manual. Human Kinetics Books, Champaign, III.
26. Cohen J (1988) Statistical power analysis for the behavioral sciences. ( $2^{\text {nd }}$ edn), Erlbaum L, Associates, Hillsdale, NJ.

27. Basciani S, Costantini D, Contini S, Persichetti A, WatanabeM, et al. (2015) Safety and efficacy of a multiphase dietetic protocol with meal replacements including a step with very low calorie diet. Endocrine 48: 863-870.

28. Lee H-C, Cheng W-Y, Hsu Y-H, et al. (2015) Effects of calorie restriction with $n-3$ long-chain polyunsaturated fatty acids on metabolic syndrome severity in obese subjects: A randomize-controlled trial. J Funct Foods 19: 929-940.

29. Nikokavoura EA, Johnston KL, Broom J, Wrieden WL, Rolland C (2015) Weight loss for women with and without polycystic ovary syndrome following a very low-calorie diet in a community-based setting with trained facilitators for 12 weeks. Diabetes Metab Syndr Obes Targets Ther 8: 495503.

30. Clément K, Viguerie N, Poitou C, Carette C, Pelloux V, et al. (2004) Weight loss regulates inflammation-related genes in white adipose tissue of obese subjects. FASEB J 18: 16571669.

31. Sasakabe T, Haimoto H, Umegaki H, Wakai K (2015) Association of decrease in carbohydrate intake with reduction in abdominal fat during 3-month moderate low-carbohydrate diet among non-obese Japanese patients with type 2 diabetes. Metabolism 64: 618-625.

32. Cicero AFG, Benelli M, Brancaleoni M, Dainelli G, Merlini D, et al. (2015) Middle and Long-Term Impact of a Very Low-Carbohydrate Ketogenic Diet on Cardiometabolic Factors: A Multi-Center, Cross-Sectional, Clinical Study. High Blood Press Cardiovasc Prev 22: 389-394.

33. Soenen S, Bonomi AG, Lemmens SG, Scholte J, Thijssen MA, et al. (2012) Relatively high-protein or "low-carb" energy-restricted diets for body weight loss and body weight maintenance? Physiol Behav 107: 374-380.

34. Clifton PM, Condo D, Keogh JB (2014) Long term weight maintenance after advice to consume low carbohydrate, higher protein diets--a systematic review and meta analysis. Nutr Metab Cardiovasc Dis 24: 224-235.

35. Mansoor N, Vinknes KJ, Veierød MB, Retterstøl K (2016) Effects of low-carbohydrate diets $v$. low-fat diets on body weight and cardiovascular risk factors: a meta-analysis of randomised controlled trials. Br J Nutr 115: 466-479.

36. Munsters MJM, Saris WHM (2014) Body weight regulation and obesity: dietary strategies to improve the metabolic profile. Annu Rev Food Sci Technol 5: 39-51.

37. Shils ME (2003) Tratado de nutriçao moderna na saude e na doença. Manole, Barueri, SP.

38. Harrington DM, Champagne CM, Broyles ST, Johnson WD, Tudor-Locke C, et al. (2015) Cardiometabolic risk factor response to a lifestyle intervention: a randomized trial. Metab Syndr Relat Disord 13: 125-131.

39. Miguel Soca PE, Peña Pérez I, Niño Escofet S, Torres C, Pena N, et al. (2012) Randomised controlled trial: the role of diet and exercise in women with metabolic syndrome. Aten Primaria 44: 387-393. 